\title{
Rapid quantitative detection of chytridiomycosis (Batrachochytrium dendrobatidis) in amphibian samples using real-time Taqman PCR assay
}

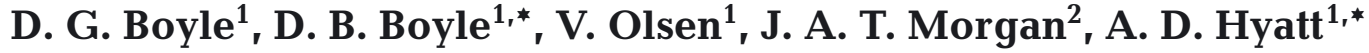 \\ ${ }^{1}$ Australian Animal Health Laboratory, CSIRO Livestock Industries, Private Bag 24, Geelong, Victoria 3220, Australia \\ ${ }^{2}$ Department of Plant and Microbial Biology, University of California, Berkeley, California 94720, USA
}

\begin{abstract}
Batrachochytrium dendrobatidis is a major pathogen of frogs worldwide, associated with declines in amphibian populations. Diagnosis of chytridiomycosis to date has largely relied upon histological and immunohistochemical examination of toe clips. This technique is invasive and insensitive particularly at early stages of infection when treatment may be possible. We have developed a real-time PCR Taqman assay that can accurately detect and quantify one zoospore in a diagnostic sample. This assay will assist the early detection of $B$. dendrobatidis in both captive and wild populations, with a high degree of sensitivity and specificity, thus facilitating treatment and protection of endangered populations, monitoring of pristine environments and preventing further global spread via amphibian trade.
\end{abstract}

KEY WORDS: Chytrids - Batrachochytrium dendrobatidis $\cdot$ Amphibian declines $\cdot$ Real-time PCR Taqman assay $\cdot$ Chytridiomycosis

\section{INTRODUCTION}

Chytridiomycosis is a serious disease of amphibians caused by the fungus Batrachochytrium dendrobatidis (Berger et al. 1998, 1999, Pessier et al. 1999). It is now believed to be responsible for widespread global declines in amphibian populations (Daszak et al. 1999). First reported in Panama and Australia in wild frog populations undergoing rapid declines, and subsequently identified in Africa, South America, Central America, North America, Europe and New Zealand (Berger et al. 1998, 1999, Lips 1999, Mutschmann et al. 2000, Bosch et al. 2001, Waldman et al. 2001, Bradley et al. 2002, Weldon 2002), the infection has been found in both wild and captive populations. Two amphibian orders (Anuran and Caudata) encompassing 14 families and 93 species have been diagnosed with infections worldwide (see www.jcu.edu.au/school/phtm/ phtm/frogs/ampdis.htm). Earliest records from archival material have been identified in North American
Rana pipiens collected in 1974 (Carey et al. 1999). Chytridiomycosis has been described as an emerging infectious disease with available evidence providing clear links to worldwide amphibian declines (Daszak et al. 2003). Multilocus sequence typing of 35 strains of $B$. dendrobatidis from North America, Africa and Australia has shown low variability of the DNA sequences among 10 loci (5918 bp), providing support for this theory (Morehouse et al. 2003).

In post-metamorphic frogs, Batrachochytrium dendrobatidis infects the keratinised epidermal cells of the frog causing a hyperkeratotic and hyperplastic response of the stratum corneum and stratum granulosum. While reasons for death are unknown, postulated causes include disruption to osmoregulation and toxin release (Daszak et al. 2001). Non-fatal infections of keratinised tadpole mouthparts have been documented with subsequent infection of the frog following metamorphosis (Berger et al. 1999, Speare 2002). Diagnosis to date has largely relied upon histological 
examination via haematoxylin and eosin staining of toe clips or skin scrapings (Daszak et al. 1999, see also www.jcu.edu.au/school/phtm/phtm/frogs/histo/ chhisto.htm). Immunoperoxidase staining with polyclonal antibodies to $B$. dendrobatidis increases the specificity and sensitivity of detection (Berger et al. 2002). More recently, a staining protocol has been described which enhances diagnosis by the colocalisation of $B$. dendrobatidis and keratin in the skin of amphibians (V. Olsen, D. Boyle, D. Mendez, A. D. Hyatt unpubl.). However, the drawbacks of histological testing include the degree of expertise needed for identification, the invasiveness of sampling technique - typically performed by toe-clipping of live animals - the length of time required, the low sensitivity of the test, and the variability of infection levels amongst toes. In the field, examination of oral disc abnormalities in tadpoles with a $10 \times$ hand lens has been recommended as a preliminary indication of chytridiomycosis (Fellers et al. 2001), although these abnormalities can also be caused by DDT intoxication. The fungus can be identified by isolation and culture (Longcore et al. 1999), but this requires a high degree of expertise and time.

Early detection of Batrachochytrium dendrobatidis is vital to the control of spread of the disease via global amphibian trade. B. dendrobatidis has been identified in animals imported for zoo collections (Pessier et al. 1999), in international pet trade (Mutschmann et al. 2000), in the food trade (Mazzoni et al. 2003) and in laboratory animal trade (Parker et al. 2002). Early detection of infection would allow possible curative treatment to be undertaken, at least in captive populations where formalin/malachite green solution has been shown to be effective on adult Xenopus tropicalis (Parker et al. 2002). Itraconazole baths $(0.01 \%)$ were found to be effective in treating the terrestrial species Dendrobates tinctorius (Nichols et al. 2001), although whether this treatment is effective and safe for use in tadpoles is yet to be determined. An elevated temperature of $37^{\circ} \mathrm{C}$ has also been suggested as an effective treatment for captive Litoria chloris (Woodhams et al. 2003). Early detection would also allow treatment and protection of endangered populations, the potential for repopulation of species from captive bred populations, and the monitoring of environments where infections have not previously been reported.

Batrachochytrium dendrobatidis has also been shown to be infective for up to $7 \mathrm{wk}$ in lake water (Johnson et al. 2003). If contamination of water, soil and animals could be sensitively detected, appropriate quarantine and disinfection strategies could be implemented to prevent further spread of disease.

A PCR-based test that would quickly identify Batrachochytrium dendrobatidis infection with a high degree of sensitivity and specificity, preferably using a non-invasive sampling method, is highly desirable. Ribosomal DNA occurs as multicopy genes in eukaryotes, typically 100 to 400 copies per haploid genome for fungi, with conserved regions for 5.8, 18 and 28S DNA separated by internal transcribed spacers (ITS-1 and ITS-2) and an intergenic spacer. Sequences of 5.8, 18 and $28 \mathrm{~S}$ rRNA molecules are highly conserved, whereas the ITS region and intergenic spacer units evolve quickly (Long et al. 1980). This variability and high copy number facilitates the design of speciesspecific PCR-based tests of high sensitivity and specificity for molecular diagnostic tests such as identification of bacteria (Barry et al. 1991, Jensen et al. 1993) and fungi (Harmsen et al. 1999, Henry et al. 2000).

Recent advances in molecular technologies have seen the development of real-time Taqman assays (Livak et al. 1995). These are faster and more sensitive than conventional PCR and allow quantitation of the target DNA, making them ideal methods for diagnostic tests. In this paper we describe a rapid, sensitive and specific Taqman assay for the quantitative detection of as little as 1 zoospore of Batrachochytrium dendrobatidis in tissues from infected frogs. The test can detect B. dendrobatidis infection in frogs 7 to 14 (or more) d before infection can be detected by histological methods.

\section{MATERIALS AND METHODS}

Cultivation of Batrachochytrium dendrobatidis and related organisms. A zoospore suspension of $B$. dendrobatidis isolate AAHL (Australian Animal Health Laboratory) 98 1810/3 from Nictimystes dayi was prepared by seeding TGhL agar plates (16 $\mathrm{g}$ tryptone, $4 \mathrm{~g}$ gelatin hydrolysate, $2 \mathrm{~g}$ lactose, $10 \mathrm{~g}$ agar, $1000 \mathrm{ml}$ distilled water) with $2 \mathrm{ml}$ of actively growing broth culture. The plates were allowed to dry until most of the solution had diffused into the agar at which time the plates were sealed, inverted and incubated at $23^{\circ} \mathrm{C}$ for $4 \mathrm{~d}$. Zoospores were harvested by flooding the plate twice with $2 \mathrm{ml}$ of DS solution (a weak salt solution resembling pond water comprising $10^{-3} \mathrm{M} \mathrm{KH}_{2} \mathrm{PO}_{4}$, $10^{-4} \mathrm{M} \mathrm{MgCl}_{2}$ and $2 \times 10^{-5} \mathrm{M} \mathrm{CaCl}_{2}$ ). Zoospore numbers were counted in a haemocytometer. Other B. dendrobatidis isolates, AAHL 98 1469/10 from a captivebred metamorph Lymnodynastes dumerilli, AAHL 00 545 from a wild-caught captive metamorph Litoria lesueuri and AAHL 99 1385/12 from wild adult Litoria caerulea, were similarly cultivated and prepared.

Five other Chytridiomycetes from the order Chytridiales: Rhizophydium sp. (JEL136), RhizophlyctisRhizophydium-like (JEL142), R. ?haynaldii (JEL151); the order Monoblepharide: Gonapodya sp. (JEL183); 
and the order Blastocladiales: Allomyces macrogynus (JEL204) (supplied by J. Longcore) were tested to verify the specificity of the Taqman assay. Cultures were grown in broth in $25 \mathrm{~cm}^{2}$ flask containing either mPmTG $(0.2 \mathrm{~g}$ peptonized milk, $0.2 \mathrm{~g}$ tryptone, $1.0 \mathrm{~g}$ glucose, $500 \mathrm{ml}$ distilled water) for JEL136, JEL142, JEL151 and JEL183 or PmTG (0.5 g peptonised milk, $0.5 \mathrm{~g}$ tryptone, $2.5 \mathrm{~g}$ glucose, $500 \mathrm{ml}$ distilled water) for JEL204. For JEL136, 142 and 151, sporangia were scraped off the flask and clumps disrupted by forcing through a 26 gauge needle 10 times. Sporangia numbers were estimated by counting in a haemocytometer. Samples of cultures (JEL142 $10^{4}$ zoosporangia, and JEL136 and JEL151 $10^{5}$ zoosporangia) were pelleted in a microfuge (Hettich, Micro 12-24) at a force of $13 \times 10^{3}$ $\times g$ for 1 min, resuspended in $200 \mu$ of PrepMan Ultra (Applied Biosystems), and DNA was extracted as detailed below. JEL183 and JEL204 grow as hyphae so individual counts were not possible. Samples containing a similar amount of fungi to the other preparations were pelleted in a microfuge and DNA-extracted in the same manner.

Frog samples. Great Barred frogs (30) Mixophyes fasciolatus were experimentally infected with $10^{4}$ zoospores from Batrachochytrium dendrobatidis isolate AAHL 98 1810/3 by bath inoculation for $20 \mathrm{~h}$. Uninfected control frogs (12) were similarly bathed in DS solution. Live infected frogs were sampled by toe clipping, as this site has been shown by histology to have a high level of infection. (Berger et al. 1998a). Two toeclips were taken at $7 \mathrm{~d}$ intervals from Day 0 to 28 . For use in real-time PCR, toes were harvested into sterile $1.5 \mathrm{ml}$ tubes and stored at $-80^{\circ} \mathrm{C}$ prior to DNA extraction. Toes to be processed for histology were fixed in $10 \%$ neutral buffered formalin.

During the course of test development, dead frogs collected in the field were submitted to the laboratory for diagnosis. Sick frogs from a breeding and research facility were also submitted. Toe clips from these frogs were processed for histology or DNA extracted as described below.

Histology. Toeclips were processed using an immunoperoxidase (IPX) staining method adapted from Berger et al. (2002). The digestion with trypsin was deleted as it was found to be unnecessary, and a DAKO Envision+ kit was used instead of the DAKO LSAB kit as it decreased incubation times.

Extraction of nucleic acid from samples. Nucleic acids were prepared from whole toes (approx. 1 to $3 \mathrm{mg}$ wet weight) by extraction with PrepMan Ultra. Forty $\mu l$ of PrepMan Ultra was added to each toe along with 30 to $40 \mathrm{mg}$ of Zirconium/silica beads measuring $0.5 \mathrm{~mm}$ diameter (Biospec Products). The toe was homogenised for $45 \mathrm{~s}$ in a Mini Beadbeater 8 (Biospec Products). After brief centrifugation (30 s at $13 \times 10^{3} \times$ $g$ in a microfuge) to recover all material to the bottom of the tube, the homogenisation and centrifugation was repeated. The homogenised toe clip was immersed in a boiling water bath for $10 \mathrm{~min}$, cooled for $2 \mathrm{~min}$, then centrifuged at $13 \times 10^{3} \times g$ for $3 \mathrm{~min}$ in a microfuge. Twenty $\mu$ l of supernatant was recovered and stored at $-80^{\circ} \mathrm{C}$.

DNA sequencing. This was performed on the 4 Batrachochytrium dendrobatidis isolates. The target DNA was amplified using BD Biosciences Advantage 2PCR Kit with primers BOB5 and BOB6 in an Applied Biosystems Gene Amp PCR System 9700 thermocycler. Products were viewed on a $1 \%$ agarose gel and the $740 \mathrm{bp}$ product was purified using a QIAquick PCR Purification kit (Qiagen). This was sequenced using an ABI Prism BigDye Terminator v1.1 Cycle Sequencing Kit run on an ABI 377XL automated sequencer with primers BOB3, 5' GCG TTC TTC ATC GTT GCG AGA GCC 3', BOB3.1, 5' AGT GCA ATG TGC GTT CAA AGA 3', BOB5, 5' ATG CTT AAG TTC AGC GGG 3' and BOB6 $5^{\prime}$ CCG ATT GAA TGG CTT AGT GAG ACC 3 '. These primers were designed from sequence data obtained from a large PCR product generated using generic primers targeting $18 \mathrm{~S}$ and 28S rDNA (J. A. T. Morgan unpubl. data).

Real-time Taqman PCR assay. Real-time Taqman PCR assays were conducted using an Applied Biosystems Prism 7700 Sequence Detection System. Twentyfive $\mu \mathrm{l}$ reactions containing $12.5 \mu \mathrm{l} 2 \times$ Taqman Master Mix (Applied Biosystems), PCR primers at a concentration of $900 \mathrm{nM}$, the MGB probe at $250 \mathrm{nM}$ and $5 \mu \mathrm{l}$ of DNA (diluted $10^{-1}$ in water) were prepared in triplicate. Included in each 96-well assay plate were control reactions containing DNA from 100, 10, 1 and 0.1 Batrachochytrium dendrobatidis genome equivalents prepared as described below and controls with no DNA template. The default ABI Prism 7700 amplification conditions $\left(2 \mathrm{~min}\right.$ at $50^{\circ} \mathrm{C}, 10 \mathrm{~min}$ at $\left.95^{\circ} \mathrm{C}\right)$, followed by $15 \mathrm{~s}$ at $95^{\circ} \mathrm{C}$ and $1 \mathrm{~min}$ at $60^{\circ} \mathrm{C}$ for 50 cycles were used. The AB 7700 instrument software calculates and plots the change in fluorescence signal from the fluorescent labelled probe $(\Delta \mathrm{Rn})$ during the PCR cycling reaction versus the cycle number. $\Delta \mathrm{Rn}$ is calculated using the equation $\Delta R n=(R n+)-(R n-)$, where $\mathrm{Rn}+$ is the fluorescence signal of the product at any given time and $\mathrm{Rn}$ - is the fluorescence signal of the baseline emission during early amplification cycles in which no fluorescence signal is detected - the instrument default setting is cycles 6 to 15 ; however, this can be adjusted if a signal is detectable before cycle 15 in any of the assays. An arbitrary threshold is then set at the midpoint of the $\log \Delta \mathrm{Rn}$ versus cycle number. The $\mathrm{Ct}$ number is defined as the cycle number at which the $\Delta \mathrm{Rn}$ crosses this threshold. Using a $\Delta \mathrm{Rn}$ of 0.10 , the $\mathrm{Ct}$ values for each test and control reaction 
a ITS-1 Chytr3

Chytr MGB2

1

GGAACTATAT TATGTCACAC GGTATACAGT GCTCAGCTTG

41 AAAATTTAтT TAтTTTTTCG AсAAAтTAAт TGgAAATTGA TTTTAAATAA ATAAAAAAgC TGtTTAATtA ACCTTtAACT ITS $-1 \mid 5.8 \mathrm{~S}$

81 ATAATTTAAT TGAAAAAAAT TGAAAATAAA TATTAAAAA I TATTAAATTA АСTTTTTTA АстTTTATTT AтAАTTTTT|G

121

AACTTTTGAC AACGGATCTC TTGGCT

TTGAAAACTG TTGCCTAGAG AACCGA

5.8S Chytr

b

Primer Sequences

29 bases

5' - CCTTGATATAATACAGTGTGCCATATGTC-3'

5.8S Chytr 22 bases

5' - AGCCAAGAGATCCGTTGTCAAA -3'

$\underline{\text { Minor groove binder probe sequence }}$

Chytr MGB2 15 bases

\section{5' - 6FAM CGAGTCGAACAAAAT MGBNFQ - 3'}

Fig. 1. Batrachochytrium dendrobatidis. rDNA sequence of internal transcribed spacer (ITS-1) and 5.8S used for design of Taqman real-time PCR primers and probe. (a) rDNA sequence including ITS-1/5.8S junction with primer and probe locations. (b) Primer sequences and minor groove binder probe sequence. GenBank accession \# AY598034

were determined. A standard curve was constructed from the control reactions containing 100, 10, 1 and 0.1 $B$. dendrobatidis zoospores and the concentration determined for the test samples expressed as the number of Zoospore equivalents.

Quantitation standards. Standards for quantitation of Batrachochytrium dendrobatidis were prepared by extraction of DNA from zoospores grown on TGhL plates as described. The zoospores were harvested from plates by washing, and counted 4 times using a haemocytometer. In all, $10^{7}$ zoospores were pelleted in a microfuge $\left(13 \times 10^{3} \times g\right.$ for $\left.1 \mathrm{~min}\right)$, the supernatant removed and the pellet resuspended in $200 \mu$ l of PrepMan Ultra. The suspension was boiled for $10 \mathrm{~min}$, cooled for $2 \mathrm{~min}$, microfuged for $3 \mathrm{~min}$, and $150 \mu \mathrm{l}$ supernatant removed. This DNA was diluted in distilled water to $2 \times 10^{5} \mathrm{ml}^{-1}$ genome equivalents, and aliquots stored at $-20^{\circ} \mathrm{C}$.

\section{RESULTS}

\section{rDNA region sequencing}

rDNA sequencing was performed on 4 Batrachochytrium dendrobatidis isolates. Sequencing of the 18S, ITS-1 and 5.8S regions was completed for these isolates, although several regions proved difficult to sequence, including a very G-rich ( 12 to $13 \mathrm{Gs})$, and an AT-rich stem/loop structure, in the ITS-1 (5'-TGTTTTTTCAAA AAACA-3'). The DNA sequence of the 4 strains was identical over the region examined. Initial attempts to design a SYBR Green and Taqman assay wholly contained within the ITS-1 were discontinued when it was found that the SYBR Green assay worked effectively but the designed Taqman assay failed, apparently due to the highly G-rich stretch and the apparent AT-rich stem/loop structure. The SYBR green assay did, however, confirm the feasibility of developing a highly sensitive test targeted to the rDNA sequences.

The final test was designed with the forward primer ITS-1 Chytr 3 and the Taqman probe Chytr MGB2 located wholly within the ITS-1 region, but excluding the G-rich stretch and the AT-rich stem/loop structure which had been identified as problematic. The reverse primer 5.8S Chytr was located within the 5.8S region immediately adjacent to the ITS-1/5.8S junction (Fig. 1). PCR amplification and sequencing of chytrid fungi rDNA sequences from skin samples and scrapings from infected frogs collected from numerous locations around Australia, Panama, USA and Ecuador showed general conservation of the sequences in the region used for the design of the assay. A total of 29 samples yielded sequence over this region; 26 of the 29 were identical to the sequence derived from the 4 Batrachochytrium dendrobatidis isolates (J.A.T. Morgan unpubl. obs.). Three of the samples had a 4 base pair deletion and 4 base pair changes in the 8 base pairs immediately adjacent to the deletion. Although located between the Taqman probe Chytr MGB2 and the 5.8S Chytr primer, this region was excluded during the primer and probe design to ensure that the assay would work on strains carrying this apparent deletion and base changes.

Blast sequence alignments of the ITS-1 and 5.8S rDNA sequences used for design of the Taqman assays showed that the ITS-1 (120 nucleotides) failed to align with existing sequences in the databases. The 5.8S rDNA (27 nucleotides) aligned exactly over the first 21 


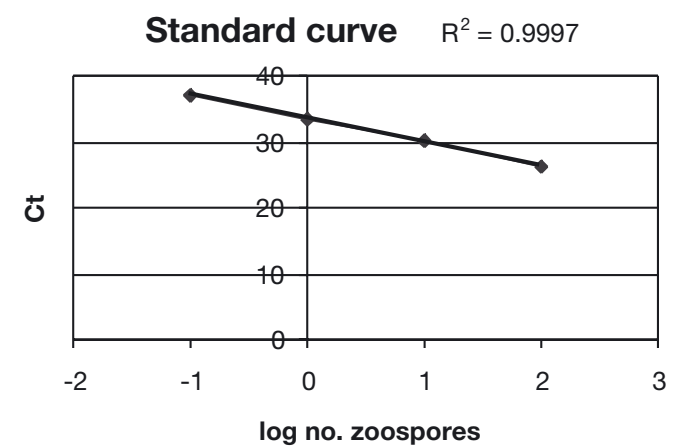

Fig. 2. Batrachochytrium dendrobatidis. Standard curve used for the determination of the pathogen in experimental samples. Plot of $\log$ no. zoospores against Ct value at $\Delta \mathrm{Rn}$ of 0.1 .

Establishment of detection limits of standards

nucleotides with Entyloma and Tilletiales speciesboth of which are classified within the Fungi Basidiomycota. This is not surprising given that $5.8 \mathrm{~S} \mathrm{rDNA}$ is highly conserved over many species. However, specificity for the test design was ensured by the location of the forward primer and probe within the unique sequences of the ITS-1 region.

\section{Sensitivity and specificity of Taqman assay}

Preliminary testing of Qiagen- and PrepMan Ultraextracted zoospores showed that both methods were effective for the extraction of DNA. PrepMan Ultra was marginally better, with mean $\mathrm{Ct}$ values 1 to 2 units lower. For speed and ease of processing, the PrepMan Ultra protocol for DNA extraction was subsequently used in all test development.

Table 1. Batrachochytrium dendrobatidis. Establishment of specificity by testing on different isolates and related organisms. Ct of 50 indicates no DNA amplification. DNA dilution of JEL142 equivalent to 10 zoospores; JEL136 and JEL151 is equivalent to 100 zoospores

\begin{tabular}{|lcc|}
\hline Order Fungus & $\mathrm{Ct}$ & $\begin{array}{c}\text { No. zoospore } \\
\text { equivalents }\end{array}$ \\
\hline Chytridiales & & \\
$\quad$ Batrachochytrium dendrobatidis Standard & 27.2 & 100 \\
(AAHL 98 1810/3) & 25 & 455 \\
B. dendrobatidis AAHL 98 1469/10 & 24.5 & 617 \\
B. dendrobatidis AAHL 00 545 & 26.4 & 222 \\
B. dendrobatidis AAHL 99 1385/12 & $>50$ & 0 \\
Rhizophydium sp. (JEL136) & $>50$ & 0 \\
Rhizophlyctis-Rhizophydium-like (JEL142) & $>50$ & 0 \\
R. ?haynaldii (JEL151) & & 0 \\
Monoblepharide & $>50$ & 0 \\
$\quad$ Gonapodya sp. (JEL183) & & \\
Blastocladiales & $>50$ & \\
$\quad$ Allomyces macrogynus (JEL204) & & \\
\hline
\end{tabular}

\section{Comparison PCR + IPX}

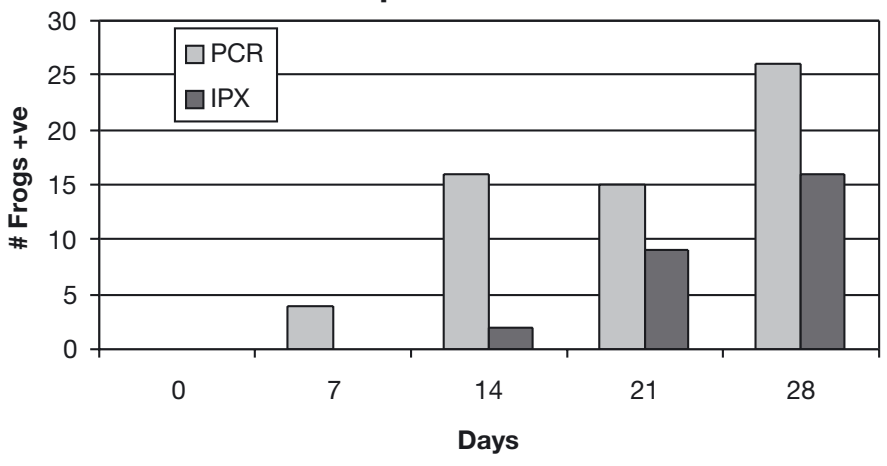

Fig. 3. Batrachochytrium dendrobatidis. Detection in frogs Mixophyes fasciolatus by PCR and IPX. Number of frogs positive by PCR or IPX at each sampling day. Number of frogs infected $=30$. All controls were negative (data not shown)

The DNA standard was diluted to give 100, 10, 1 and 0.1 genome equivalents for use in the Taqman assay. These give reproducible results (Fig. 2), with an $\mathrm{R}^{2}$ consistently close to 1 . Dilutions of 0.01 genome equivalents could be detected, but the accuracy and reproducibility was not as great, so this dilution was not included for quantitation purposes. At these low dilutions, the assay detects Batrachochytrium dendrobatidis, but quantification is not accurate. For analysis of test samples, extracted DNA was diluted $10^{-1}$ in water, and $5 \mu \mathrm{l}$ of this dilution used in a $25 \mathrm{ul} \mathrm{PCR} \mathrm{reaction,} \mathrm{as}$ higher concentrations of PrepMan Ultra reagent were found to be inhibitory (authors' unpubl. data).

Specificity was confirmed by use of 3 other isolates of Batrachochytrium dendrobatidis (AAHL 98 1469/10, AAHL 99 1385/12 and AAHL 00 545) and 5 other fungi from the Chytridiomycetes. The $3 \mathrm{~B}$. dendrobatidis isolates were all detected by the assay, while none of the other fungi were amplified (Table 1).

\section{Comparative evaluation of Taqman assay and histology}

Experimental infection of frogs was used to compare the current histological method of diagnosis with the Taqman assay. Fig. 3 shows detection of Batrachochytrium dendrobatidis as early as $7 \mathrm{~d}$ post-infection using the Taqman assay. By $14 \mathrm{~d}_{\text {, }}$ infection was detected in more than half the frogs using this assay, compared with infection in only 2 of 30 frogs detected by histology. For most frogs, B. dendrobatidis could 
Table 2. Batrachochytrium dendrobatidis quantitation in frogs. Numbers for PCR are numbers of zoospore equivalents as determined in Taqman assay. Numbers for IPX (immunoperoxidase) are numbers of sporangia observed per toe clip. All controls were negative (data not shown). All frogs were negative by both methods at Day 0 (data not shown)

\begin{tabular}{|c|c|c|c|c|c|c|c|c|}
\hline Frog no. & $\begin{array}{l}\text { Day } \\
\text { PCR }\end{array}$ & $\begin{array}{c}7 \\
\text { IPX }\end{array}$ & $\begin{array}{l}\text { Day } \\
\text { PCR }\end{array}$ & $\begin{array}{l}14 \\
\text { IPX }\end{array}$ & $\begin{array}{l}\text { Day } \\
\text { PCR }\end{array}$ & $\begin{array}{l}21 \\
\text { IPX }\end{array}$ & $\begin{array}{l}\text { Day } \\
\text { PCR }\end{array}$ & $\begin{array}{l}28 \\
\text { IPX }\end{array}$ \\
\hline 1 & - & - & 85 & - & 190 & - & - & 3 \\
\hline 3 & - & - & - & - & 1430 & - & 7 & - \\
\hline 4 & - & - & 31 & - & 14 & - & 1660 & 51 \\
\hline 5 & - & - & 469 & - & - & - & 145 & - \\
\hline 8 & - & - & - & - & - & - & 29 & 6 \\
\hline 11 & - & - & 318 & - & - & - & 602 & 4 \\
\hline 12 & - & - & - & - & 1890 & - & 1910 & 29 \\
\hline 14 & - & - & 300 & - & 45940 & - & 1460 & 14 \\
\hline 15 & 178 & - & 618 & - & 5700 & 14 & 439 & 38 \\
\hline 16 & - & - & 43 & - & - & - & 1790 & 17 \\
\hline 18 & - & - & 296 & - & - & 4 & 157 & 11 \\
\hline 19 & - & - & 260 & - & - & - & 229 & 4 \\
\hline 20 & - & - & - & - & - & - & 7 & - \\
\hline 21 & 125 & - & 2 & - & 174 & 3 & 343 & 30 \\
\hline 24 & - & - & 5 & - & - & - & 1550 & - \\
\hline 25 & - & - & - & - & 1190 & 5 & 70 & 5 \\
\hline 26 & - & - & 237 & - & 5280 & 12 & 1010 & 7 \\
\hline 27 & - & - & - & - & 25 & 10 & 500 & - \\
\hline 29 & 29 & - & 1050 & 22 & 56 & - & 128 & - \\
\hline 30 & - & - & - & - & - & - & 380 & - \\
\hline 32 & - & - & - & - & - & - & 19 & - \\
\hline 33 & - & - & - & - & - & 2 & 16 & - \\
\hline 36 & 2 & - & 321 & 1 & 2440 & 25 & 518 & 13 \\
\hline 37 & - & - & 46 & - & - & - & 2 & - \\
\hline 39 & - & - & - & - & 2 & - & 1260 & - \\
\hline 41 & - & - & 421 & - & 1 & - & 5 & - \\
\hline 42 & - & - & - & - & 6 & 15 & 2000 & 56 \\
\hline
\end{tabular}

Analysis of diagnostic samples confirmed that the Taqman assay could sensitively detect Batrachochytrium dendrobatidis from field samples. These samples were in poor condition, being desiccated and covered in mud. At low levels of infection, the Taqman assay was more sensitive than IPX. In 3 of the field samples, B. dendrobatidis was detected by PCR but not IPX, and in the captive bred submissions 1 sample was similarly positive by PCR and not IPX. There was a good correlation in these samples between high PCR numbers and detection by IPX staining (Table 3).

\section{DISCUSSION}

Improvements to histological methods for diagnosis of Batrachochytrium dendrobatidis infection have been made using polyclonal antibodies and dual staining procedures to detect keratin as well as B. dendrobatidis. However, these methods are relatively slow, taking several days for diagnosis, and require an expert diagnostician to make the identification. Variability between levels of infection on toeclips, the need for serial sectioning and examination of many slides for detection of $B$. dendrobatidis infection (particularly at early stages of infection), and the desirability of noninvasive testing of frogs led to the development of a rapid, sensitive PCR-based assay. The high abundance (several hundred copies per genome) and the speciesspecificity of rDNA ITS in eukaryotic organisms pro- be detected using the Taqman assay 2 wk prior to detection by IPX (Table $2)$, although there were some anomalies (Frogs 18 and 33 at Day 21) where sporangia were detected at low levels by IPX, but not in the Taqman assay. This was not surprising given that the assays were conducted on different toe clips, and at low levels of infection some toes may be infected while others are not. High PCR results did not correlate to IPX detection in $30 \%$ of frogs; even at the highest detected numbers (Frog 14, Day 21), when it would be reasonable to expect a positive IPX result, none were observed. This, again, is probably a reflection of the sampling method, where one toe may be infected whereas another is not. Also, the toe clips were not serially sectioned through the whole toe, so some infections may not have been detected.
Table 3. Frog species submitted for diagnosis with results of IPX and real-time PCR. IPX results are as follows:,+ 1 to 10 sporangia;,++ 11 to 100 sporangia; ,$+++ 100+$ sporangia; ?+, ambiguous result. Numbers for PCR are numbers of zoospore equivalents, nd: not determined

\begin{tabular}{|lccc|}
\hline Species & & IPX results & Real-time PCR \\
\hline Lymnodynastes dumerilii & Wild & ++ & 910 \\
Lymnodynastes dumerilii & Wild & + & 25800 \\
Lymnodynastes peroni & Wild & - & 10 \\
Crinia signifera & Wild & nd & 12 \\
Litoria reniformis & Wild & - & 0 \\
Lymnodynastes dumerilii & Wild & - & 1052 \\
Litoria tasmanionsis & Wild & +++ & 333579 \\
Litoria tasmanionsis & Wild & +++ & 153361 \\
Litoria infrafrenata & Captive-bred & - & - \\
Litoria infrafrenata & Captive-bred & - & - \\
Litoria caerulea & Captive-bred & - & - \\
Litoria infrafrenata & Captive-bred & - & - \\
Litoria infrafrenata & Captive-bred & - & - \\
Lymnodynastes peroni & Captive-bred & + & 933 \\
Lymnodynastes dumerilii & Captive-bred & $?+$ & - \\
Mixophyes fasciolatus & Captive-bred & + & 1450 \\
Mixophyes fasciolatus & Captive-bred & - & 10 \\
Litoria ewingi & Captive-bred & ++ & 88800 \\
Litoria ewingi & Captive-bred & + & 13 \\
Litoria ewingi & Captive-bred & + & 201 \\
\hline
\end{tabular}


vided the opportunity to design a real-time Taqman assay with high specificity and sensitivity for $B$. dendrobatidis.

The specificity of our Taqman assay was confirmed by testing on 3 other Batrachochytrium dendrobatidis isolates and 5 other members of the Chytridiales order. The assay detected all of the 3 other isolates of B. dendrobatidis. Morehouse et al. (2003) found extremely low variability during multilocus sequence typing of 35 strains of B. dendrobatidis from North America, Africa and Australia. We therefore expect that this Taqman assay will detect all strains of $B$. dendrobatidis worldwide. High conservation of the rDNA sequence in the ITS-1 region used to design the Taqman assay was observed in 26 of 29 sequences obtained from frog samples from Australia and the Americas. None of the 5 other members of the Chytridiales order were detected in the assay. Although this is not a comprehensive analysis of all closely related fungi, phylogenetic analysis of 54 chytrids identified JEL142 and JEL151 as the most closely related to B. dendrobatidis (James et al. 2000). Neither of these fungi, nor the other 3 species tested, were detected in our assay. As many fungi may opportunistically infect the skin of sick frogs potentially producing false positives, the lack of detection of these closely related fungi gives confidence in the specificity of the assay.

The high copy number of the ITS-1 region facilitates the detection of low numbers of organisms, as seen by the ability to reliably detect a nominal amount of 0.1 genome equivalents of Batrachochytrium dendrobatidis. This allows the detection of infection at much lower levels than is possible with histology, where the chances of detecting 1 sporangium on a toe clip are quite small unless the whole toe is serially sectioned and examined. Additionally, there are up to 10 zoospores in each sporangia (Berger et al. 2000), giving several hundred targets in a DNA-based assay, compared with 1 sporangium by histology. This sensitivity has been demonstrated by the detection of infection in experimentally infected animals as early as $7 \mathrm{~d}$ postinfection and at least $2 \mathrm{wk}$ prior to detection by histological methods. Additionally, the Taqman assay is rapid in comparison to histology. It is possible to extract and quantify up to 27 samples in less than $4 \mathrm{~h}$, a process that would take several days by histology.

Variability of infection among toe clips remains a problem in the diagnosis of chytridiomycosis. This was exemplified in 6 individuals in our study by the detection by PCR of infection at Day 14, no detection at Day 21, and detection again at Day 28. This is probably a result of low levels of infection, where some toes of the same individual are infected whilst others are not. To overcome this problem, alternative sampling methods, such as baths and swabs, where the whole frog is sampled in a non-destructive manner, are being assessed to determine optimum sampling regimes. Preliminary data suggest these methods will be more sensitive than toe clipping, more reliable, as they sample the entire frog, and obviously less destructive to the animal.

The Taqman assay was shown to be applicable to field samples, even those in sub-optimal condition, and again was more sensitive than histology. Fungal DNA is stable, allowing detection even in degraded samples. The presence or absence of Batrachochytrium dendrobatidis was confirmed on captive-bred animals. The ability of an assay to detect low levels of organisms at an early stage of infection is vital to prevent the spread of infection between tanks in breeding facilities. It would also allow isolation and possible treatment of infected frogs.

When optimum sampling protocols and the Taqman assay are applied to screening frog populations, we will have powerful tools to help prevent the spread of Batrachochytrium dendrobatidis. Quarantine regimes applicable to movement of zoo animals, pets, laboratory animals and the food trade will be able to be implemented. Early detection will allow early treatment and protection of endangered species, and possible repopulation of species into depopulated habitats from captive breeding populations. Application of the assay to environmental samples may lead to a greater understanding of the process of infection and help prevent its spread, particularly to areas not already infected.

Acknowledgements. This work was supported by funding from Integrated Research Challenges in Environmental Biology (IRCEB) Grant IBN-9977063 from the National Science Foundation, USA. We are grateful to J. Longcore for providing other Chytridiomycetes used in this study. We thank D. Furness and S. Goldie for assistance with animal experiments, L. Berger for reading IPX slides and G. Marantelli from Amphibian Research Centre, Melbourne, Australia, for providing infected frogs.

\section{LITERATURE CITED}

Barry T, Colleran G, Glennon M, Dunican LK, Gannon F (1991) The 16s/23s ribosomal spacer region as a target for DNA probes to identify eubacteria. PCR Methods Appl 1: $51-56$

Berger L, Speare R (1998) Chytridiomycosis - a new disease of amphibians. ANZCCART News 11:1-3

Berger L, Speare R, Daszak P, Green DE and 10 others (1998) Chytridiomycosis causes amphibian mortality associated with population declines in the rain forests of Australia and Central America. Proc Natl Acad Sci 95:9031-9036

Berger L, Speare R, and Hyatt AD (1999) Chytrid fungi and amphibian declines: overview, implications and future directions. In: Campbell A (ed) Declines and disappearances of Australian frogs. Environment Australia, Canberra, p 23-33 
Berger L, Speare R, Kent A (2000) Diagnosis of chytridiomycosis in amphibians by histologic examination. Zoos' Print Journal XV:184-190

Berger L, Hyatt AD, Olsen V, Hengstberger SG, Boyle D, Marantelli G, Humphreys K, Longcore JE (2002) Production of polyclonal antibodies to $B$. dendrobatidis and their use in an immunoperoxidase test for chytridiomycosis in amphibians. Dis Aquat Org 48:213-20

Bosch J, Martínez-Solano I, García-París M (2001) Evidence of a chytrid fungus infection involved in the decline of the common midwife toad (Alytes obstetricans) in protected areas of central Spain. Biol Conserv 97:331-337

Bradley GA, Rosen PC, Sredl MJ, Jones TR, Longcore JE (2002) Chytridiomycosis in native Arizona frogs. J Wildl Dis 38:206-212

Carey C, Cohen N, Rollins-Smith L (1999) Amphibian declines: an immunological perspective. Dev Comp Immunol 23:459-472

Daszak P, Berger L, Cunningham AA, Hyatt AD, Green DE, Speare R (1999) Emerging infectious diseases and amphibian population declines. Emerging Infect Dis 5: 735-748

Daszak P, Cunningham AA, Hyatt AD (2001) Anthropogenic environmental change and the emergence of infectious diseases in wildlife. Acta Trop 78:103-116

Daszak P, Cunningham AA, Hyatt AD (2003) Infectious disease and amphibian population declines. Div Distrib 9: 141-150

Fellers GM, Green DE, Longcore JE (2001) Oral Chytridiomycosis in the Mountain Yellow-Legged Frog (Rana muscosa). Copeia 4:945-953

Harmsen D, Schwinn A, Brocker EB, Frosch M (1999) Molecular differentiation of dermatophyte fungi. Mycoses 42:67-70

Henry T, Iwen PC, Hinrichs SH (2000) Identification of Aspergillus species using internal transcribed spacer regions 1 and 2. J Clin Microbiol 38:1510-1515

James TY, Porter D, Leander CA, Vilaglys R, Longcore JE (2000) Molecular phylogenetics of the Chytridiomycota supports the utility of ultrastructural data in chytrid systematics. Can J Bot 78:336-350

Jensen MA, Webster JA, Straus N (1993) Rapid identification of bacteria on the basis of polymerase chain reactionamplified ribosomal DNA spacer polymorphisms. Appl Environ Microbiol 59:945-952

Johnson ML, Speare R (2003) Survival of Batrachochytrium dedrobatidis in water: quarantine and disease control

Editorial responsibility: Peernel Zwart,

Utrecht, The Netherlands implications. Emerging Infect Dis 9:922-925

Lips K (1999) Mass mortality and population declines of anurans at an upland site in western Panama. Conserv Biol 13: $117-125$.

Livak KJ, Flood SJ, Marmaro J, Giusti W, Deetz K (1995) Oligonucleotides with fluorescent dyes at opposite ends provide a quenched probe system useful for detecting PCR product and nucleic acid hybridization. PCR Methods Appl 4:357-362

Long EO, Dawid IB (1980) Repeated genes in eukaryotes. Annu Rev Biochem 49:727-764

Longcore JE, Pessier AP, Nichols DK (1999) Batrachochytrium dendrobatidis gen. et sp. nov., a chytrid pathogenic to amphibians. Mycologia 91:219-227

Mazzoni R, Cunningham AA, Daszak P, Apolo A, Perdomo E, Speranza G (2003) Emerging pathogen of wild amphibians in frogs (Rana catesbeiana) farmed for international trade. Emerging Infect Dis 9:995-998

Morehouse EA, James TY, Ganley AR, Vilgalys R, Berger L, Murphy PJ, Longcore JE (2003) Multilocus sequence typing suggests the chytrid pathogen of amphibians is a recently emerged clone. Mol Ecol 12:395-403

Mutschmann F, Berger L, Zwart P, Gaedicke C (2000) Chytridiomycosis in amphibians-first report in Europe. Berl Munch Tieraerztl Wochenschr 113:380-383

Nichols DK, Lamirande EW, Pessier AP, Longcore JE (2001) Experimental transmission of cutaneous chytridiomycosis in dendrobatid frogs. J Wildl Dis 37:1-11

Parker JM, Mikaelian I, Hahn N, Diggs HE (2002) Clinical diagnosis and treatment of epidermal chytridiomycosis in African clawed frogs (Xenopus tropicalis). Comp Med 52: 265-268

Pessier AP, Nichols DK, Longcore JE, Fuller MS (1999) Cutaneous chytridiomycosis in poison dart frogs (Dendrobates spp.) and White's tree frogs (Litoria caerulea). J Vet Diagn Invest 11:194-199

Waldman B, van de Wolfshaar KE, Klena JD, Andjic V, Bishop P, Norman RJ de B (2001) Chytridiomycosis in New Zealand frogs. Surveillance 28:9-11

Weldon C (2002) Chytridiomycosis survey in South Africa. Froglog, Newsletter of the Declining Amphibian Population Task Force 51:2. Dept Biological Science, Milton Keynes

Woodhams DC, Alford RA, Marantelli G (2003) Emerging disease of amphibians cured by elevated body temperature. Dis Aquat Org 55:65-67

Submitted: January 6, 2004; Accepted: April 12, 2004

Proofs received from author(s): July 19, 2004 